www.jmscr.igmpublication.org

Impact Factor (SJIF): 6.379

Index Copernicus Value: 79.54

ISSN (e)-2347-176x ISSN (p) 2455-0450

crossrefDOI: https://dx.doi.org/10.18535/jmscr/v6i10.01

Journal Of Medical Science And Clinical Research

IGM Publication

An Official Publication of IGM Publication

\title{
Knowledge of hypoglycemia and its associated risk factors among type 2 diabetes Mellitus patients in diabetes Centre, Security Forces Hospital, Riyadh, Saudi Arabia
}

\author{
Author \\ Naif Mohammed Albaqami
}

Family Medicine Resident

\begin{abstract}
Background: Hypoglycemia is the most common and serious side effect of glucose-lowering medications and considered the rate-limiting side effect in achieving tight glycemic control in Diabetes Mellitus (DM). Diabetes-related hypoglycemia has both short-term and long-term complications. Moreover, hypoglycemia episodes, especially the severe ones, lead to a considerable increase in both direct and indirect medical care costs

Objectives: Primary objective: Study the knowledge about hypoglycemia among type 2 diabetic patients attending the diabetes centre clinics, F \& CM Department at SFH, Riyadh.

Secondary objectives: To assess the most common causes, symptoms and prevalence of hypoglycemia among type 2 diabetes patients in SFH.

Methods: Cross-sectional study among Type 2 diabetic patients visiting the diabetes centre clinics at SFH in 2017

Results: Of 386 participants, 237 participants (61.4\%) had good knowledge of hypoglycemia, but only 149 participants $(38.6 \%)$ had poor knowledge. The mean age, weight and height of participants were $53.7 \pm 13.5$ years, $80 \pm 27.2 \mathrm{Kg}$ and $158 \pm 21 \mathrm{~cm}$. According to participants' opinion about the most common cause of hypoglycemia is exertion (68.7\%) and most common symptom of hypoglycemia is dizziness (74.6\%).239 (61.9\%) experienced a hypoglycemic event in the last three months; and, the majority of them, 126 (52.7\%) had less than three times attacks of hypoglycemia, and only 107 (27.7\%) had no previous hypoglycemia in the last three months.

Conclusion: Participants had good knowledge about hypoglycemia and its preventive method. However, increasing incidence of hypoglycemic events needs more diabetes education programs to apply their knowledge on a daily routine.

Keywords: Diabetes, hypoglycemia, type 2, symptoms, prevalence.
\end{abstract}

\section{Introduction}

Hypoglycemia has been defined by both the American Diabetes Association (ADA) and the European Medicines Agency as "any abnormally low plasma glucose concentration that exposes the subject to potential harm" with a proposed threshold plasma glucose value $<70 \mathrm{mg} / \mathrm{dL}(<3.9$ $\mathrm{mmol} / \mathrm{L})^{[1,2]}$. Hypoglycemia, a frequently underestimated problem, is the most common and serious side effect of glucose-lowering medications and considered the rate-limiting side effect in achieving tight glycemic control in 
Diabetes Mellitus (DM). Repeated hypoglycemic episodes can adversely affect the counterregulatory system resulting in significant morbidity and mortality which is reportedly associated with a six-fold increase in death ${ }^{[3,4]}$. Diabetes-related hypoglycemia has both shortterm and long-term complications including cerebrovascular disease, cardiovascular diseases, retinal cell death, vision loss, and neurocognitive dysfunction in addition to health-related quality of life issues ${ }^{[5]}$. Moreover, hypoglycemia episodes, especially the severe ones, lead to a considerable increase in both direct and indirect medical care costs $^{[6,7]}$.

Evidence from previous observational studies indicates that hypoglycemia risk is particularly high among patients who are on insulin treatment ${ }^{[8-10]}$, and have a longer diabetes duration and longer duration of insulin treatment ${ }^{[8]}$. Although occurring more frequently in type 1 diabetes, hypoglycemia also is clinically important in type 2 diabetes. In regards to hypoglycemia among type $2 \mathrm{DM}$, it has been previously reported that hypoglycemia requiring emergency assistance from health service personnel is as frequent in insulin-treated type 2 diabetes people as in type 1 diabetes people ${ }^{[9]}$. Prevalence and incidence of hypoglycemia were high among insulin-treated patients with diabetes in Canada, and some patients took harmful or costly actions when they experienced hypoglycemia ${ }^{[11]}$, another study done in UK on 2003 concluded the prevalence of severe hypoglycemia was $7.3 \%$ in patients with T2DM treated with insulin, and $0.8 \%$ in patients with T2DM treated with sulfonylurea ${ }^{[9]}$. Similarly, a previous study in Denmark among type 2 DM indicated that there was at least one episode of severe hypoglycemia in $16.5 \%$ of patients with an incidence of 44 episodes/100 patient years ${ }^{[10]}$.

Generally, hypoglycemia in DM patients occurs when there is an imbalance between insulin/hypoglycemic agent's intake and the body's physiological need. The reasons that could account for hypoglycemia in diabetic patients are Iatrogenic, Diet changes and infections ${ }^{[18]}$.

\section{Literature Review}

This systematic literature investigated Knowledge of hypoglycemia and its associated risk factors among type 2 diabetes Mellitus patients in diabetes Centre in the kingdom of Saudi Arabia. Searches were done by reviewing journals and articles found in PubMed database. Several articles that were not accessible by full text from the databases were obtained using Google Scholar. Based on the results of Kedia N study ${ }^{[20]}$, overall, the most common identified cause of severe hypoglycemia among type 2 diabetic patients were: insufficient food consumption (47\% in T2DM), followed by physical exercise (23\%), insulin dose miscalculation (16\%), stressful situations (17\%), oscillating blood glucose levels $(8 \%)$ and impaired hypoglycemia awareness $(5 \%)$ $\mathrm{T}_{2} \mathrm{DM}^{[20]}$

In India, study included 366 type 2 diabetic patients, $242(66.1 \%)$ diabetic patients had good knowledge on hypoglycemia (knowledge of at least three symptoms of hypoglycemia together with at least one precipitating factor and at least one remedial measure ${ }^{[22]}$

In Arar, Saudi Arabia, a study conducted to to assess the awareness of the Arar population with various aspects of diabetes mellitus., the study results in out of 702 participants The majority (86.3) of the participants believed that the treatment of DM was a combination of healthy diet, exercise and medication and more than half $(63.1 \%)$ said that weight loss and modification of life style were the most important preventive measures of DM. Regarding participants' knowledge about DM complications, 24.5\% knew about retinopathy and loss of vision, $8.3 \%$ knew about retinopathy, loss of vision, low sensation and numbness in extremities, $24.9 \%$ said that symptoms of DM were thirst and frequent urination $^{\text {[23] }}$

The Kingdom of Saudi Arabia ranked to be the seventh among the top ten countries with high diabetes prevalence ${ }^{[24]}$. 


\section{Patients \& Methods}

Study design and duration

Cross-sectional study, from 1st May 2017 -1st of

November 2017

\section{Results}

\section{Patient baseline characteristics}

Out of 386 participants, the mean age, weight and height of participants were $53.7 \pm 13.5$ years, $80 \pm 27.2 \mathrm{Kg}$ and $158 \pm 21 \mathrm{~cm}$, respectively. This section in our questionnaire was designed to assess the socio-demographic features of our participants. It involved 10 questions which were answered by participants. Responses to each question were listed in Table (1). The data was expressed as (frequency and percent). Male participants $257(66.6 \%)$ were higher than female 129 (33.4\%). Most participants aged between 5160 years 122 (31.6\%). Obesity was high among participants 238 (61.4\%). Most of our participants had diabetes less than five years ago 177 (45.7\%).

Table 1 socio-demographic feature of participants among type 2 diabetes Mellitus patients in diabetes Centre, Security Forces Hospital, Riyadh, Saudi Arabia

\begin{tabular}{|l|c|c|}
\hline & No & $\%$ \\
\hline Age* & & \\
\hline $20-30$ & 52 & 13.6 \\
\hline $31-40$ & 51 & 13.3 \\
\hline $41-50$ & 55 & 14.2 \\
\hline $51-60$ & 122 & 31.4 \\
\hline$>60$ & 106 & 27.5 \\
\hline BMI* & & \\
\hline Normal weight & 84 & 21.9 \\
\hline Overweight & 64 & 16.7 \\
\hline Obese & 238 & 61.4 \\
\hline Gender & & \\
\hline Male & 257 & 66.6 \\
\hline Female & 129 & 33.4 \\
\hline Marital status* & & \\
\hline Single & 62 & 15.9 \\
\hline Married & 255 & 65.8 \\
\hline Divorced & 39 & 7.7 \\
\hline Widowed & 40 & 10.6 \\
\hline Job title* & & \\
\hline Student & 50 & 12.9 \\
\hline Civilian job & 75 & 19.5 \\
\hline Military officer & 74 & 19.2 \\
\hline Military field & 103 & 26.7 \\
\hline
\end{tabular}

\begin{tabular}{|l|c|c|}
\hline Retried & 65 & 16.7 \\
\hline Unemployed & 19 & 5 \\
\hline Education level & & \\
\hline Illiterate & 139 & 35.9 \\
\hline Primary/secondary & 74 & 19.3 \\
\hline University & 108 & 28 \\
\hline Post graduate & 65 & 16.8 \\
\hline $\begin{array}{l}\text { Socioeconomic level* } \\
\text { (SAR) }\end{array}$ & & \\
\hline$<5000$ & 150 & 38.5 \\
\hline $5000-10000$ & 53 & 13.8 \\
\hline $10000-15000$ & 139 & 33.5 \\
\hline$>15000$ & 54 & 14.2 \\
\hline Diabetes duration & & \\
\hline$<5$ & 177 & 45.7 \\
\hline $5-10$ & 82 & 21.3 \\
\hline$>10$ & 127 & 33 \\
\hline Diabetes treatment* & & \\
\hline Diet & 83 & 21.5 \\
\hline Oral & 117 & 30.3 \\
\hline Insulin & 95 & 24.7 \\
\hline Oral and insulin & 91 & 23.5 \\
\hline
\end{tabular}

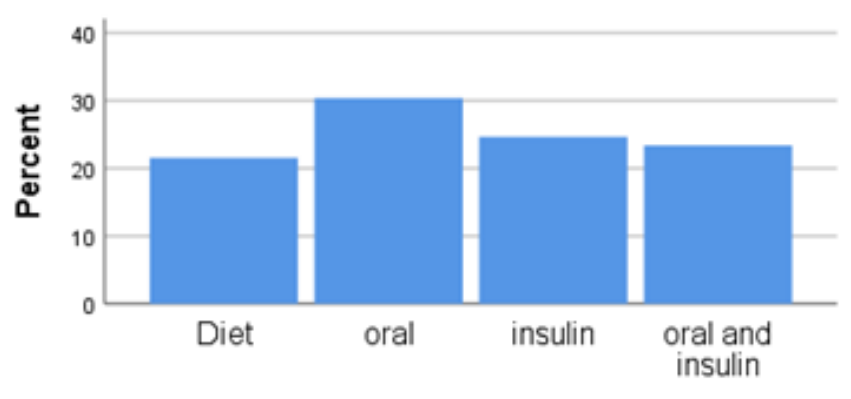

Diabetes treatment

Figure 1 diabetes treatment regimen among type 2 diabetes Mellitus patients in diabetes Centre, Security Forces Hospital, Riyadh, Saudi Arabia.

Table 2 prevalence and frequency of hypoglycemia events among type 2 diabetes Mellitus patients in diabetes Centre, Security Forces Hospital, Riyadh, Saudi Arabia

\begin{tabular}{|c|c|c|}
\hline \multirow{2}{*}{$\begin{array}{l}\text { Hypoglycemia event in the last } \\
3 \text { months (out of } 386 \text { patients) }\end{array}$} & No & $\%$ \\
\hline & & \\
\hline Yes & 239 & 61.9 \\
\hline No & 107 & 27.8 \\
\hline Don’t know & 40 & 10.3 \\
\hline $\begin{array}{l}\text { Hypoglycemia frequency (out } \\
\text { of } 239 \text { patients) }\end{array}$ & & \\
\hline$<3$ & 126 & 52.7 \\
\hline $3-6$ & 75 & 31.3 \\
\hline$>6$ & 38 & 16 \\
\hline
\end{tabular}




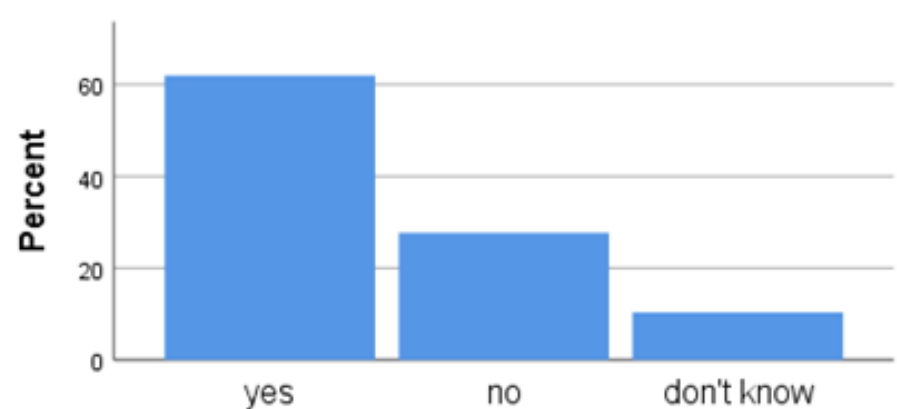

Hypoglycemic event

Table 3 Knowledge of symptoms of hypoglycemia among type 2 diabetes Mellitus patients in diabetes Centre, Security Forces Hospital, Riyadh, Saudi Arabia

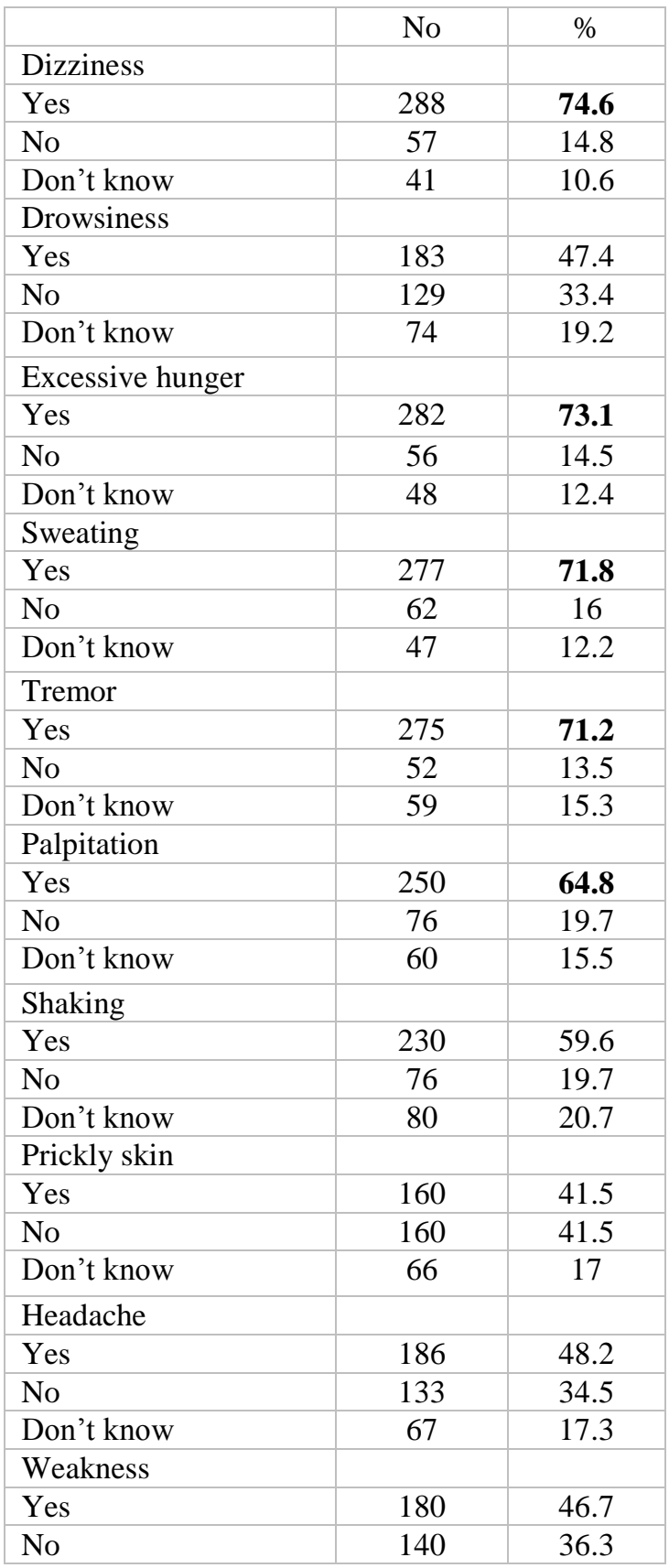

\begin{tabular}{|l|c|c|}
\hline Don't know & 66 & 17 \\
\hline Loss of consciousness & & \\
\hline Yes & 178 & 46.1 \\
\hline No & 153 & 39.6 \\
\hline Don't know & 55 & 14.3 \\
\hline Confusion & & \\
\hline Yes & 225 & 58.3 \\
\hline No & 96 & 24.9 \\
\hline Don't know & 65 & 16.8 \\
\hline Irritability & & \\
\hline Yes & 167 & 43.3 \\
\hline No & 147 & 38 \\
\hline Don't know & 72 & 18.7 \\
\hline Blurred vision & & \\
\hline Yes & 214 & 55.4 \\
\hline No & 102 & 26.4 \\
\hline Don't know & 70 & 18.2 \\
\hline Aggression & & \\
\hline Yes & 154 & 39.9 \\
\hline No & 153 & 39.6 \\
\hline Don't know & 79 & 20.5 \\
\hline Slurred speech & & \\
\hline Yes & 187 & 48.4 \\
\hline No & 121 & 31.4 \\
\hline Don't know & 78 & 20.2 \\
\hline & & \\
\hline
\end{tabular}

Table 4 Knowledge of precipitating factor of hypoglycemia among type 2 diabetes Mellitus patients in diabetes Centre, Security Forces Hospital, Riyadh, Saudi Arabia

\begin{tabular}{|l|c|c|}
\hline Missing or delaying food & No & $\%$ \\
\hline Yes & 262 & 67.9 \\
\hline No & 79 & 20.5 \\
\hline Don't know & 45 & 11.6 \\
\hline Exertion & & \\
\hline Yes & 265 & $\mathbf{6 8 . 7}$ \\
\hline No & 68 & 17.6 \\
\hline Don't know & 53 & 13.7 \\
\hline Wrong Dose & & \\
\hline Yes & 216 & 56 \\
\hline No & 97 & 25.1 \\
\hline Don't know & 73 & 18.9 \\
\hline Alcohol ingestion & & \\
\hline Yes & 135 & 35 \\
\hline No & 109 & 28.2 \\
\hline Don't know & 142 & 36.8 \\
\hline
\end{tabular}


Table 5 Knowledge of complications of hypoglycemia among type 2 diabetes Mellitus patients in diabetes Centre, Security Forces Hospital, Riyadh, Saudi Arabia

\begin{tabular}{|l|c|c|}
\hline & No & $\%$ \\
\hline Paralytic attack & & \\
\hline Yes & 109 & 28.3 \\
\hline No & 129 & 33.4 \\
\hline Don't know & 148 & 38.3 \\
\hline Heart attack & & \\
\hline Yes & 116 & 30 \\
\hline No & 160 & 41.5 \\
\hline Don't know & 110 & 28.5 \\
\hline Coma & & \\
\hline Yes & 161 & 41.7 \\
\hline No & 122 & 31.6 \\
\hline Don't know & 103 & 26.7 \\
\hline Fits & & \\
\hline Yes & 141 & 36.5 \\
\hline No & 144 & 37.3 \\
\hline Don't know & 101 & 26.2 \\
\hline Death & & \\
\hline Yes & 179 & $\mathbf{4 6 . 2}$ \\
\hline No & 80 & 20.6 \\
\hline Don't know & 129 & 33.2 \\
\hline
\end{tabular}

\section{Knowledge of action taken during an attack of hypoglycemia}

Table 6 Knowledge of action taken during the attack of hypoglycemia among type 2 diabetes Mellitus patients in diabetes Centre, Security Forces Hospital, Riyadh, Saudi Arabia

\begin{tabular}{|l|l|l|}
\hline \multicolumn{1}{|l|}{} & No & $\%$ \\
\hline Eat sweets/ chocolates/ biscuits & & \\
\hline Yes & 222 & 57.5 \\
\hline No & 80 & 20.7 \\
\hline Don't know & 84 & 21.8 \\
\hline Eat food & & \\
\hline Yes & 213 & 55.2 \\
\hline No & 99 & 25.6 \\
\hline Don't know & 74 & 19.2 \\
\hline Drink glucose* & & \\
\hline Yes & 182 & 48 \\
\hline No & 99 & 25.6 \\
\hline Don't know & 98 & 25.4 \\
\hline Drink sugar syrup/ juices/milk & & \\
\hline Yes & 230 & $\mathbf{5 9 . 6}$ \\
\hline No & 89 & 23 \\
\hline Don't know & 67 & 17.4 \\
\hline Use glucagon injection & & \\
\hline Yes & 208 & 53.9 \\
\hline No & 74 & 19.2 \\
\hline Don't know & 104 & 26.9 \\
\hline *7subjects with missing data & & \\
\hline
\end{tabular}

$* 7$ subjects with missing data

\section{Knowledge of prevention from hypoglycemia}

Table 7 Knowledge of prevention from hypoglycemia among type 2 diabetes Mellitus patients in diabetes Centre, Security Forces Hospital, Riyadh, Saudi Arabia

\begin{tabular}{|c|c|c|}
\hline & No & $\%$ \\
\hline \multicolumn{3}{|l|}{ Take timely meals } \\
\hline Yes & 270 & 69.9 \\
\hline No & 44 & 11.4 \\
\hline Don't know & 72 & 18.7 \\
\hline \multicolumn{3}{|l|}{$\begin{array}{l}\text { Take medication as advised } \\
\text { by the doctor }\end{array}$} \\
\hline Yes & 274 & 71 \\
\hline No & 65 & 16.8 \\
\hline Don’t know & 47 & 12.2 \\
\hline \multicolumn{3}{|l|}{$\begin{array}{l}\text { Report low sugar episode to } \\
\text { the doctor to adjust the } \\
\text { medications* }\end{array}$} \\
\hline Yes & 268 & 74.1 \\
\hline No & 38 & 9.8 \\
\hline Don't know & 62 & 16.1 \\
\hline \multicolumn{3}{|l|}{$\begin{array}{l}\text { Self-monitoring of blood } \\
\text { sugars }\end{array}$} \\
\hline Yes & 288 & 74.6 \\
\hline No & 46 & 11.9 \\
\hline Don't know & 52 & 13.5 \\
\hline
\end{tabular}

Table 8 source of Knowledge about hypoglycemia among type 2 diabetes Mellitus patients in diabetes Centre, Security Forces Hospital, Riyadh, Saudi Arabia

\begin{tabular}{|l|l|l|}
\hline & No & $\%$ \\
\hline 1 & 148 & $\mathbf{3 8 . 4}$ \\
\hline 2 & 24 & 6.2 \\
\hline 4 & 60 & $\mathbf{1 5 . 5}$ \\
\hline 5 & 6 & 1.6 \\
\hline 6 & 13 & 3.4 \\
\hline 8 & 6 & 1.6 \\
\hline 12 & 6 & 1.6 \\
\hline 124 & 6 & 1.6 \\
\hline 1246 & 7 & 1.8 \\
\hline 135 & 7 & 1.8 \\
\hline 14 & 31 & $\mathbf{8}$ \\
\hline 145 & 7 & 1.8 \\
\hline 1456 & 6 & 1.6 \\
\hline 15 & 13 & 3.4 \\
\hline 17 & 7 & 1.8 \\
\hline 18 & 6 & 1.6 \\
\hline 45 & 12 & 3.1 \\
\hline 48 & 7 & 1.8 \\
\hline 56 & 14 & 3.6 \\
\hline Total & 386 & 100 \\
\hline
\end{tabular}

1 doctor, 2 fellow patient, 3 relative, 4 TV/radio, 5 magazine, 6 diabetes educator,7 nurse/paramedics, 8 hospital charts/boards 


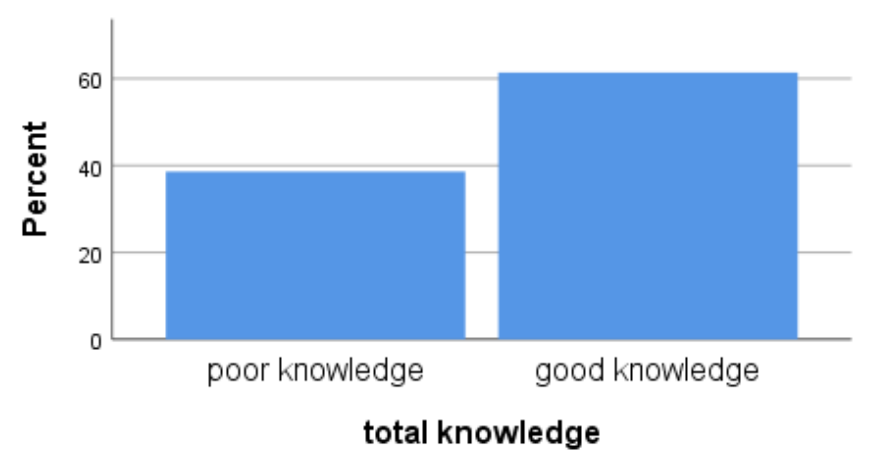

Figure 3 Composite score for knowledge about diabetes among type 2 diabetes Mellitus patients in diabetes Centre, Security Forces Hospital, Riyadh, Saudi Arabia.

\section{Discussion}

In this study, we concern about hypoglycemia in type 2 diabetic patient as it is one of the most important complications of diabetes treatment. Episodes hypoglycemia may lead to impairment of counter-regulatory system, with the potential of development of hypoglycemia unawareness. So, hypoglycemia may increase the vascular events even death in addition to other possible detrimental effects. The significant finding in our results is that there was an adequate total knowledge $61.4 \%$ (273/386) of diabetes regarding symptoms, precipitating factors, complications, action taken during attacks and methods of prevention. Another study conducted in a primary care centre in eastern Saudi Arabia to assess Knowledge of diabetes risk factors and preventive measures among attendees 121 participants (42.0\%) had knowledge of DM risk factors and $120(41.7 \%)$ had knowledge of DM prevention [25].

Despite the fact that the cause of DM is unknown, many of its modifiable lifestyle-related risk factors have been identified and studied. The most common known cause of hypoglycemia was exertion $(68.7 \%)$ followed by missing or delaying food (67.9\%). These results in accordance to The accumulating evidence suggests that DM is a potentially preventable disease if its risk factors are identified early and avoided ${ }^{[26-29]}$ Lifestyle interventions (e.g. physical activity, weight loss) have proven to be more effective than medicine in preventing or delaying the onset of DM in persons at high risk of developing the disease.

Our results showed that dizziness is the most common cause of hypoglycemia (74.6\%) between diabetic patients followed by excessive hunger (73.1\%), sweating (71.8\%) and tremor (71.2\%).n associated cause was reported by 147 (57.0\%) of 258 patients who reported hypoglycemia. Retrospective, cross-sectional analysis set in an outpatient specialty diabetes clinic assumed that the most common event associated with hypoglycemia was a missed meal (119 patients [80.9\%]), followed by use of medications in doses higher than those prescribed (8 patients [5.4\%]), exercise (5 patients [3.4\%]), and other (12 patients $[8.2 \%])^{[30]}$.

In general, the frequency of hypoglycemia is lower in people with type 2 diabetes than Type 1 [31]. However the prevalence of type 2 diabetes is about twenty-fold higher than type 1 diabetes, and many patients with type 2 diabetes finally require treatment with insulin; therefore most episodes of hypoglycemia occur in patients with type 2 diabetes. Our results show a high incidence of hypoglycemia (61.9\%) with less than three times frequency $(70.6 \%)$ over the last three months prior to the initiation of the study. However, patients in the insulin-treated groups had a higher prevalence of hypoglycemia than patients in the diet-only group $(30.5 \% \quad[193 / 633]$ vs $11.8 \%$ [9/76]; $\mathrm{P}<.001$ ), and patients treated with a combination of insulin, metformin, and sulfonylurea (triple therapy) had a 2-fold increase in any hypoglycemia compared with other patients treated with insulin $(61.5 \%$ [8/13] vs $29.8 \%$ [185/620]; $\mathrm{P}=.01)^{[32]}$.

Severe hypoglycemia has a considerable impact on wellbeing, productivity and quality of life in old people with diabetes [33]. Hypoglycemia can lead to many complications especially in elderly people ${ }^{[13]}$. Most common complications known by our participants are fits (37.1\%) and death $(47.1 \%)$. 
Doctors $(38.4 \%)$ are the most common source of knowledge in participants' answers. Television and radio is the second source of information represented $(15.5 \%)$. Healthcare providers were the preferred source of information on driving and diabetes for $78 \%$ of drivers ${ }^{[31]}$. Nearly two-thirds of family members and friends actively sought information about hypoglycemia, while health professionals and print media were reported as the main sources ${ }^{[35]}$.

Limitations of our study include its cross-sectional design, which prevents an exact calculation of incidence of hypoglycemia and therefore prohibits direct comparison of the results of our study with other study designs. In addition, the data rely on patients' abilities to remember and interpret symptoms as a consequence of low blood glucose levels. Consistent with earlier studies and routine practice, which rely on patient self-reports to make clinical decisions; our results reflect information that is clinically relevant and available to most practitioners. Another limitation may be that most of our participants are Saudi in Riyadh city. Although we do not know whether our results can be generalized to other populations.

\section{Conclusion}

Hypoglycemia can be an important limiting factor in the treatment of patients with type 2 diabetes. Despite slightly good knowledge among participants about hypoglycemia, they also had a high incidence of hypoglycemic events. Educational programmers are needed to encourage patients to apply their knowledge in practical life and to ensure the dangerous consequence of a low blood sugar level can be avoided.

\section{References}

1. Association, A.D., Defining and reporting hypoglycemia in diabetes: a report from the American Diabetes Association Workgroup on Hypoglycemia. Diabetes Care, 2005. 28(5): p. $1245-1249$.
2. EMA, C., Guideline on similar biological medicinal products containing monoclonal antibodies-non-clinical and clinical issues: http://www. ema. Europe. eu/docs/en_GB/document_library/Scientific_ guideline/2012/06/WC500128686. pdf. 2012, EMA/CHMP/BMWP/403543/2010. London, 30 May.

3. Noh, R.M., A.J. Graveling, and B.M. Frier, Medically minimising the impact of hypoglycaemia in type 2 diabetes: a review. Expert opinion on pharmacotherapy, 2011. 12(14): p. 2161-2175.

4. Griesdale, D.E., et al., Intensive insulin therapy and mortality among critically ill patients: a meta-analysis including NICESUGAR study data. Canadian Medical Association Journal, 2009. 180(8): p. 821827.

5. Kalra, S., et al., Hypoglycemia: The neglected complication. Indian journal of endocrinology and metabolism, 2013. 17(5): p. 819.

6. Lundkvist, J., et al., The economic and quality of life impact of hypoglycemia. The European journal of health economics, 2005. 6(3): p. 197-202.

7. Jönsson, L., B. Bolinder, and J. Lundkvist, Cost of hypoglycemia in patients with Type 2 diabetes in Sweden. Value in health, 2006. 9(3): p. 193-198.

8. Abbatecola, A.M., et al., Severe hypoglycemia is associated with antidiabetic oral treatment compared with insulin analogs in nursing home patients with type 2 diabetes and dementia: results from the DIMORA study. J Am Med Dir Assoc, 2015. 16(4): p. 349 e 7-12.

9. Leese, G.P., et al., Frequency of severe hypoglycemia requiring emergency treatment in type 1 and type 2 diabetes: a populationbased study of health service resource use. Diabetes care, 2003. 26(4): p. 1176-1180.

10. Akram, K., et al., Frequency and risk factors of severe hypoglycaemia in insulin- treated 
Type 2 diabetes: a cross- sectional survey. Diabetic medicine, 2006. 23(7): p. 750-756.

11. Aronson, R., et al., The Canadian Hypoglycemia Assessment Tool Program: Insights Into Rates and Implications of Hypoglycemia From an Observational Study. Can J Diabetes, 2018. 42(1): p. 11-17.

12. Larijani, B., Journal of diabetes and metabolic disorders: launch editorial. 2012, BioMed Central.

13. Kedia, N., Treatment of severe diabetic hypoglycemia with glucagon: an underutilized therapeutic approach. Diabetes, metabolic syndrome and obesity: targets and therapy, 2011. 4: p. 337. .

14. Shriraam V, Mahadevan S, Anitharani M, Jagadeesh NS, Kurup SB, Vidya TA, Seshadri KG. Knowledge of hypoglycemia and its associated factors among type 2 diabetes mellitus patients in a tertiary care hospital in South India. Indian journal of endocrinology and metabolism. 2015 May;19(3):378

15. Alanazi AM, el-Fetoh NM, Alotaibi HK, Alanazi KA, Alotaibi BK, Alshammari SM, Alanazi SR, Alhazmi MD, Alshammari YT, Alshammari ZQ. Survey of awareness of diabetes mellitus among the Arar population, Northern Border Region of Saudi Arabia. Electronic physician. 2017 Sep;9(9):5369.

16. Federation, I.D., IDF diabetes atlas -7 th edition. 2015.

17. Rowe, B.H., et al., Acute management and outcomes of patients with diabetes mellitus presenting to Canadian emergency departments with hypoglycemia. Can J Diabetes, 2015. 39 Suppl 4: p. 9-18.

18. Cha, S.A., et al., Severe Hypoglycemia and Cardiovascular or All-Cause Mortality in Patients with Type 2 Diabetes. Diabetes Metab J, 2016. 40(3): p. 202-10.

19. Gillies, C.L., et al., Pharmacological and lifestyle interventions to prevent or delay type 2 diabetes in people with impaired glucose tolerance: systematic review and metaanalysis. Bmj, 2007. 334(7588): p. 299.

20. Lindström, J., et al., The Finnish Diabetes Prevention Study (DPS): Lifestyle intervention and 3-year results on diet and physical activity. Diabetes care, 2003. 26(12): p. 3230-3236.

21. Prevention, D., Programme (DPP) Research Group. The Diabetes Prevention Program (DPP). Description of lifestyle intervention. Diabetes Care, 2002. 25: p. 2165-2171.

22. Takai, M., et al., A case of hypothalamic hypopituitarism accompanied by recurrent severe hypoglycemia. Springerplus, 2015. 4: p. 173.

23. Dalal, M.R., et al., Hypoglycemia After Initiation of Basal Insulin in Patients with Type 2 Diabetes in the United States: Implications for Treatment Discontinuation and Healthcare Costs and Utilization. Adv Ther, 2017. 34(9): p. 2083-2092.

24. Miller, C.D., et al., Hypoglycemia in patients with type 2 diabetes mellitus. Archives of internal medicine, 2001. 161(13): p. 16531659.

25. Davis, R.E., et al., Impact of hypoglycaemia on quality of life and productivity in type 1 and type 2 diabetes. Current medical research and opinion, 2005. 21(9): p. 1477-1483.

26. Feher, M.D., H. Langerman, and M. Evans, Hypoglycemia, diabetes therapies and driving categories in type 2 diabetes. Curr Med Res Opin, 2016. 32(6): p. 1005-12.

27. Reifegerste, D. and S. Hartleib, Hypoglycemia-related information seeking among informal caregivers of type 2 diabetes patients: Implications for health education. $\mathbf{J}$ Clin Transl Endocrinol, 2016. 4: p. 7-12. 